\title{
Cavalo de troia na inovação curricular: sentidos materializados em sala de aula
}

\author{
Trojan horse in curricular Innovation: Meanings materialized in the classroom \\ Caballo del troya en la innovación curricular: sentidos materializados en el aula
}

Gilberto Tadeu Reis da Silva

ORCID: https://orcid.org/0000-0002-0595-0780

Universidade Federal da Bahia, Brasil

E-mail: gilberto.tadeu@ufba.br

Deybson Borba de Almeida

ORCID: https://orcid.org/0000-0002-2311-6204

Universidade Estadual de Feira de Santana, Brasil

E-mail: dbalmeida@uefs.br

Elaine Kelly Nery Carneiro

ORCID: https://orcid.org/0000-0002-5279-8363

Universidade Federal da Bahia, Brasil

E-mail: lanenery@hotmail.com

Núbia Lino de Oliveira

ORCID: https://orcid.org/0000-0003-0088-972X

Universidade Federal da Bahia, Brasil

E-mail: nubialinodeoliveira@gmail.com

Silvana Lima Vieira

ORCID: https://orcid.org/0000-0002-9663-3691

Universidade do Estado da Bahia, Brasil

E-mail: silvana.limavieira@gmail.com

Ises Adriana Reis dos Santos

ORCID: https://orcid.org/0000-0002-5858-5537

Universidade Federal da Bahia, Brasil

E-mail: ises.adriana.reis@gmail.com

Ludmila Anjos de Jesus

ORCID: https://orcid.org/0000-0002-4471-6057 Universidade Federal da Bahia, Brasil

E-mail: ludmila.anjos27@gmail.com

Itanna Vytoria Sousa Serra

ORCID: https://orcid.org/0000-0002-6781-7336 Universidade Federal da Bahia, Brasil

E-mail: itannaserra@gmail.com

Monalisa Viana Sant'Anna

ORCID: https://orcid.org/0000-0003-3336-2510 Universidade Federal da Bahia, Brasil

E-mail: santannamonalisa7@gmail.com

Alexandre Silva Santos

ORCID: https://orcid.org/0000-0002-2187-2065 Universidade Federal da Bahia, Brasil

E-mail: alexandres.adm@gmail.com

Erica Luzia Sales Murici de Jesus

ORCID: https://orcid.org/0000-0001-6814-7103 Universidade Federal da Bahia, Brasil

E-mail: ericamurici@gmail.com

Ingredy Nayara Chiacchio Silva

ORCID: https://orcid.org/0000-0003-1815-8650 Universidade Federal da Bahia, Brasil E-mail: ingredy.cs@gmail.com

\section{Resumo}

Objetivo: relatar os sentidos manifestos por discentes do componente Inovação Curricular e Formação em Saúde em um Programa de Pós-Graduação de uma Universidade Federal no nordeste brasileiro. Metodologia: relato de experiência produzido a partir de aula temática acerca das inovações curriculares, desenvolvida com a participação dos discentes de um programa de pós-graduação em enfermagem e saúde na modalidade stricto sensu. Os dados foram coletados e discutidos a partir da análise semiótica de imagens paradas nos desenhos elaborados pelos participantes após a problematização do assunto. Resultados: pode-se afirmar que novas propostas para a educação têm redirecionado o processo de aprendizagem, contudo há coexistência de modelos e oportunidades habituais e inovadores, sendo que a formação tradicional é representada de forma mais evidente, mesmo quando tratada como 
uma possibilidade transformadora. Considerações finais: constatou-se o convívio de diversas teorias curriculares no ideário dos discentes de pós-graduação stricto sensu, que apesar dos avanços, a prática pedagógica tradicional ainda interfere de modo hegemônico na condução do processo ensino-aprendizagem, o que demanda uma reorientação da formação de modo a promover uma mudança consciente e sólida no processo educativo.

Palavras-chave: Criatividade; Educação superior; Currículo; Aprendizagem.

\begin{abstract}
Objective: to report the meanings manifested by students of the Curricular Innovation and Health Training component in a Graduate Program of a Federal University in northeastern Brazil. Methodology: report of experience produced from a thematic class on curricular innovations, developed with the participation of students of a graduate program in nursing and health in the stricto sensu modality. Data were collected and discussed from the semiotic analysis of images still in the drawings elaborated by the participants after the problematization of the subject. Results: it can be affirmed that new proposals for education have redirected the learning process, however there is coexistence of usual and innovative models and opportunities, and traditional training is represented more clearly, even when treated as a transformative possibility. Final considerations: it was verified the conviviality of several curricular theories in the ideary of the stricto sensu graduate students, that despite the advances, the traditional pedagogical practice still interferes in a hegemonic way in the conduction of the teaching-learning process, which requires a reorientation of the training in order to promote a conscious and solid change in the educational process.
\end{abstract}

Keywords: Creativity; Higher education; Curriculum; Learning.

\title{
Resumen
}

Objetivo: reportar los significados manifestados por los estudiantes del componente de Innovación Curricular y Capacitación en Salud en un Programa de Posgrado de una Universidad Federal en el noreste de Brasil. Metodología: informe de experiencia producido a partir de una clase temática sobre innovaciones curriculares, desarrollada con la participación de estudiantes de un programa de posgrado en enfermería y salud en la modalidad stricto sensu. Los datos fueron recolectados y discutidos a partir del análisis semiótico de imágenes aún en los dibujos elaborados por los participantes después de la problematización del sujeto. Resultados: se puede afirmar que las nuevas propuestas de educación han redirigido el proceso de aprendizaje, sin embargo, hay coexistencia de modelos y oportunidades habituales e innovadores, y la formación tradicional se representa con mayor claridad, incluso cuando se trata como una posibilidad transformadora. Consideraciones finales: se verificó la convivencia de varias teorías curriculares en la idea de los estudiantes de posgrado stricto sensu, que a pesar de los avances, la práctica pedagógica tradicional aún interfiere de manera hegemónica en la conducción del proceso de enseñanza-aprendizaje, lo que requiere una reorientación de la formación con el fin de promover un cambio consciente y sólido en el proceso educativo.

Palabras clave: Creatividad; Educación superior; Plan de estudios; Aprendizaje.

\section{Introdução}

No decorrer das últimas décadas a sociedade vem sofrendo profundas transformações no quesito aquisição e desenvolvimento de conhecimentos, tanto pela multiplicidade de fontes produtoras como pela maior facilidade e agilidade de acesso à informação. Tais transformações modificam as práticas usuais das pessoas, inclusive no contexto acadêmico, onde essas mudanças advêm rapidamente. Esta perspectiva, ademais, tem sido considerada como um aspecto relevante, dada a necessidade de integração entre as diversas áreas do saber.

Assim, define-se a sociedade do conhecimento como uma sociedade de aprendizagem (Silva, 2011). Nesse âmbito, destaca-se que, no processo formativo essas reformas também são fundamentais, uma vez que a reorganização da sociedade interfere diretamente nas necessidades do mercado de trabalho, bem como nas relações sociais (Trotte et al., 2021; Siqueira Silva, Xavier \& Almeida, 2020; da Silva et al., 2020).

Diante do exposto, o Ensino Superior precisa desenvolver novas estratégias e caminhos para a formação, visto que esta não pode se esgotar em habilidades técnicas e científicas, mas deve se adequar às novas exigências e permitir a apreensão de outras competências e aprendizagens que renovem sua prática (Mancilla, Backes \& Canever, 2020; Scarton et al, 2020; Backes et al, 2015). Nesse sentido, tal formação precisa transcender uma ação pontual, como algo que gere conhecimentos e resolutividade coletiva.

O tema inovação tem sido discutido há mais de uma década no ambiente acadêmico, visando à formação de profissionais críticos e criativos, conscientes de sua responsabilidade ética, política e profissional (Hargreaves, 2004; Netto, 
Silva \& Rua, 2018; Macedo et al, 2018). Contudo, apresenta-se como um resultado direto da tecnologia derivada da ciência e como um processo de pesquisa que impulsiona o desenvolvimento econômico e social (Audy, 2017). No entanto, a inovação não deve ser traduzida simplesmente como uma novidade, ou uso de determinada tecnologia e dinâmica, mas sim, como uma forma de aprendizagem que possibilite aos educandos e educadores o enfrentamento crítico das mudanças da atual sociedade (Hargreaves, 2004).

Assim, a inovação curricular parte de sua contextualização na sociedade contemporânea, desta forma, o currículo é concebido como um conjunto de aprendizagens que, num dado tempo, contexto social e profissional, mostram-se imprescindíveis (Masetto, 2006). Nesse sentido, a participação ativa de professores e alunos na elaboração/execução e avaliação curricular se faz imprescindível (Hargreaves, 2004; Masetto, 2006). Similarmente, torna-se importante destacar que na área da enfermagem, em especial, a ação do profissional não perpassa apenas pelo fazer, mas pelo saber porque o faz.

Destarte, este trabalho fundamentou-se nas três teorias curriculares de Sacristán (2000): 1) teoria tradicional - com foco principal na formação do trabalhador especializado ou em proporcionar à população uma educação geral e acadêmica, com valorização, sobretudo, da eficiência, sendo organizada de forma mecânica e burocrática; 2) teorias críticas - concentramse no questionamento do conhecimento corporificado no currículo e deslocam a ênfase dos conceitos simplesmente pedagógicos de ensino e aprendizagem para os conceitos de ideologia e poder; e 3) teorias pós-críticas - apresentam um currículo menos estruturalista, consideram as conexões entre significação, identidade e poder e, compreendem que o currículo está irremediavelmente envolvido nos processos de formação pelos quais nos tornamos o que somos.

A teoria curricular de Sacristán (2000), proporciona um olhar crítico e arrojado para o currículo, em particular na discussão acerca do uso de novas abordagens para o ensino-aprendizagem, mais condizentes com as atuais necessidades.

Para ilustrar essa teoria, fez-se, neste estudo, uma analogia com a história contada por Homero, na obra Ilíada da mitologia grega, a respeito da estratégia de guerra do Cavalo de Troia, quando o exército grego deixou para os troianos de "presente" um enorme cavalo de madeira como símbolo da paz (Mendes, 2012). Na época, enquanto os troianos festejavam a suposta vitória na guerra, foram surpreendidos por milhares de soldados gregos que estavam escondidos dentro deste cavalo. Nesse sentido, a inovação curricular pode ser considerada um "presente de grego", com intenções e efeitos distintos a depender de quem oferece, do receptor e do contexto em que é aplicada.

Nesse jogo de metáforas, podemos associar os currículos e as estruturas formativas a Troia, cidade rodeada por fortalezas que protegiam um poderoso reino com estruturas sólidas e hegemônicas, inabalável por muitos anos. Romper essas estruturas requer astúcia, criatividade, inovação e um exército de guerreiros que podemos nomear, no campo da formação, de educadores, gestores e educandos.

Assim como na guerra de Troia, a qual não foi iniciada por embate, mas sim com estratégia, há que se levar em consideração, no contexto formativo, as adaptações conforme os contextos sociais, políticos, de relações e de interesses muitas vezes ocultos, de modo a continuamente romper as estruturas e implantar inovações nesse ambiente, que se encontra em constante disputa.

Diante do exposto, o presente estudo tem por objetivo relatar os sentidos manifestos por discentes do componente Inovação Curricular e Formação em Saúde em um Programa de Pós-Graduação de uma Universidade Federal no nordeste brasileiro.

\section{Metodologia}

Relato de experiência, considerado um estudo que trata de um domínio social, no contexto das experiências humanas sob o ponto de vista das observações realizadas sob um determinado fenômeno (Lopes, 2012). Para esse fim, fundamentou-se na vivência de discentes de Pós-graduação em Enfermagem stricto sensu no componente Inovação Curricular e Formação em 
Saúde de uma Universidade Federal no nordeste brasileiro, no ano de 2019. A referida disciplina é ofertada como componente optativo, que possui, em sua composição, carga horária de 51 horas e pauta-se no desenvolvimento presencial de atividades compostas por diálogos expositivos, seminários e discussões temáticas.

Os encontros ocorreram em sala de aula da referida universidade, com a presença de alunos regulares e especiais da pós-graduação. Como ponto de partida para a produção deste artigo, adotou-se a discussão do tema "Inovação Curricular na Educação Superior e a Formação do Professor" com base nos desenhos problematizadores elaborados pelos discentes.

Para tanto, tal dinâmica ocorreu em dois momentos distintos. Inicialmente, o docente que ministrou a temática solicitou a formação de quatro grupos, os quais foram divididos de maneira aleatória. Em seguida, após orientação para o desenvolvimento da atividade, os participantes foram estimulados a colocar em prática a reflexão, criticidade e criatividade, sendo orientado que elaborassem cartazes para ilustrar os significados da inovação curricular e seus desdobramentos, utilizando linguagem verbal e não verbal.

$\mathrm{Na}$ sequência, foram disponibilizados materiais didáticos (papéis, cartazes e canetas coloridas) para que cada grupo expressasse a temática livremente, utilizando esses recursos para criar desenhos ou escrever palavras. Nos casos em que a escolha foi o emprego das palavras, os discentes apresentaram suas ideias sobre o processo de inovação curricular em um texto de até 10 linhas.

Neste contexto, tem-se no mister dos estudos qualitativos a possibilidade de exploração de conteúdos não verbais, a exemplo das imagens. Isso permite integrar diversas informações em um todo organizado, o que não é possível apenas por meio da simples descrição verbal (Gondim, Feitosa \& Chaves, 2007).

Para a coleta dos dados, utilizou-se o método qualitativo, apoiado por um corpus materializado nos elementos "escrito e oral" apresentados em sala de aula pelos discentes, incluindo os desenhos elaborados e a discussão entre os grupos acerca do assunto.

Para a apreciação dos desenhos, aplicou-se o método descrito por Bauer e Gaskell (2008), definido como análise semiótica de imagens paradas, produzida a partir da discussão do sistema linguístico de signos e a mediação entre o significante e o significado. Além disso, o presente estudo foi embasado pelas três teorias curriculares de Sacristán (2000): (tradicionais; críticas e pós-críticas).

Quanto aos aspectos éticos, por se tratar de um relato de experiência exclusivamente dos discentes autores deste estudo, sem possibilidade de identificação individual, não foi preciso aplicar o Termo de Consentimento Livre e Esclarecido e não houve necessidade de aprovação prévia por parte de um Comitê de Ética em Pesquisa. De acordo com o estabelecido nas Resoluções 466/12 e 510/16 do Conselho Nacional de Saúde, garantiu-se a confidencialidade dos participantes e resguardou-se o sigilo das informações fornecidas em confiança (Brasil, 2012, 2016).

\section{Resultados}

O presente relato de experiência descreve os significados da Inovação Curricular para os discentes do componente Inovação Curricular e Formação em Saúde em um Programa de Pós-Graduação stricto sensu de uma Universidade Federal no nordeste brasileiro. Para tanto, fundamenta-se nas três teorias curriculares de Sacristán (2000).

Ao apresentar suas percepções acerca da temática problematizada, cada grupo de discentes pôde escolher uma denominação para os desenhos elaborados, conforme está apresentado no Imagem 1: Figura 1 Inovação e interação; Figura 2 Inovação em processo; Figura 3 Tópicos para a inovação e; Figura 4 Inovação - processo ascendente. 
Imagem 1 - Apresentação dos desenhos elaborados pelos discentes segundo os significados da inovação curricular.

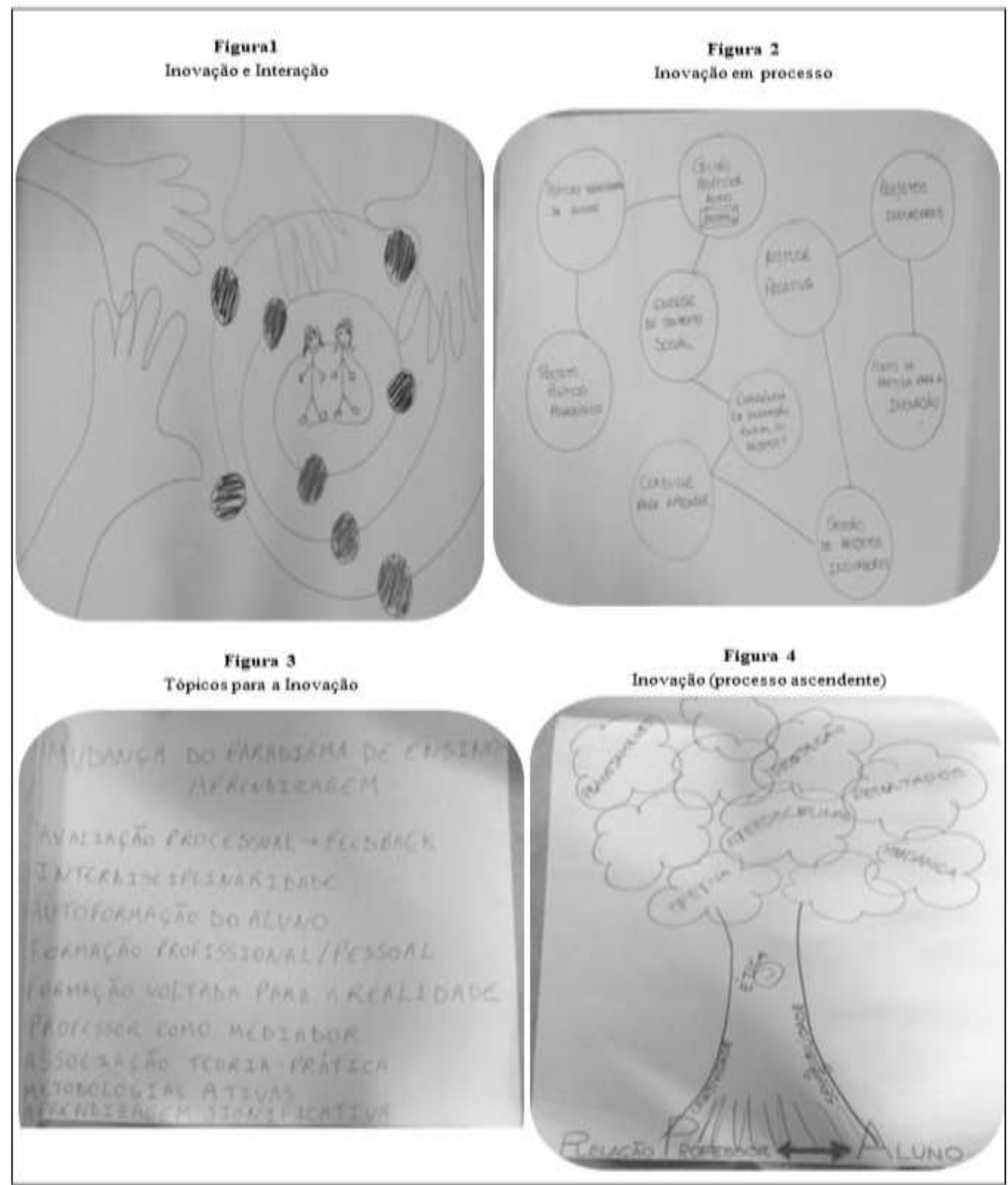

Fonte: Autores.

\section{Discussão}

As teorias curriculares relacionam-se ao contexto sociopolítico e cultural, sendo afetadas e reformuladas conforme a conjuntura histórica e as necessidades do mercado. Neste estudo, quando correlacionadas as teorias curriculares às percepções apresentadas nos desenhos, evidenciou-se, nas figuras traços da teoria curricular tradicional, na qual afirma-se que "o currículo" aparece, assim, como o conjunto de objetivos de aprendizagens selecionadas, os quais devem dar lugar à criação de experiências apropriadas e com efeitos cumulativos avaliáveis e, desse modo possa manter o sistema numa revisão constante, onde se operem as oportunas reacomodações" (Sacristán, 2000, p. 46).

Os elementos da prática pedagógica tradicional também se mostraram presentes nos desenhos, com destaque, quando comparada às outras teorias na Figura 4. Esta teoria propõe que o desenvolvimento do currículo responda a quatro questões principais (Sacristán, 2000): quais objetivos educacionais a escola deve procurar atingir? Quais experiências educacionais podem ser oferecidas para o alcance desses propósitos? Como organizar eficientemente essas experiências educacionais? Como podemos ter certeza de que os objetivos estão sendo alcançados? 
A teoria curricular tradicional, influenciada pelos princípios Tayloristas, pauta-se na transmissão de conhecimentos centrada na figura do professor, como emissor e detentor do saber e do aluno como receptor passivo dos conhecimentos (Aguiar, 2017). Ademais, há a valorização dos aspectos quantitativos da avaliação, em detrimento da capacidade crítica, reflexiva e de transformação do educando. Por conseguinte, a educação configura-se como mecanizada, e com ênfase na eficiência dos resultados de maneira similar ao modelo de produção capitalista.

A partir das figuras, foi perceptível a presença de elementos que remetem ao ensino em progressão, com a compartimentalização de saberes e práticas. E, aponta para um processo de ensinagem, no qual ocorre o isolamento entre o professor e o estudante, além de haver a mecanização e foco no planejamento, organização e avaliação do processo educativo, com o intuito de alcançar a eficiência.

Assim, os aspectos do modelo tradicional de ensino, caracterizados por deficiências na qualificação de práticas pedagógicas inovadoras, pela centralidade do professor no processo de ensino-aprendizagem, e na transmissão de conteúdos abordados numa perspectiva tecnicista, ainda ocupam posição de destaque no panorama atual (Costa, 2018).

Nesse contexto, a teoria tradicional considera o conhecimento como estático, prioriza as questões técnicas e o preparo do indivíduo para o trabalho, destoando da educação como instrumento que possibilite a transformação da realidade pelo educando (Aurélio Silva, Kayser \& Braga, 2018).

As figuras 2 e 3 são as que mais se aproximam das questões expressas no contexto social que abrange a teoria crítica. Tal teoria busca discutir as questões ideológicas e o contexto social e político, com vistas à construção de currículos mais aproximados da realidade e da necessidade social dos discentes (Malta, 2013).

Dos elementos da teoria crítica, também evidenciados nos desenhos, podemos destacar: conscientização e identificação das relações sociais, políticas e cultura para inovação curricular, com destaque para as questões ideológicas, de emancipação e libertação dos sujeitos envolvidos no processo de ensino. Essa teoria objetivava um novo modo de teorização e um novo paradigma, rompendo com o modelo tradicional de pensar (Baltar, 2020).

O sentido epistemológico da Teoria Crítica consiste na consolidação de uma teoria social, capaz de pensar por contradição e contestar a teoria social hegemônica, de perspectiva positivista, que Horkheimer (1990) denomina de Teoria Tradicional. Para tanto, os professores precisam adotar uma postura autocrítica para a construção de uma sociedade mais justa, digna, livre e democrática (Habowski \& Conte, 2019).

Além disso, as figuras 1 e 4 explicitam elementos da teoria pós-crítica como a subjetividade e o saber-poder, sob forte influência do pós-modernismo e do pós-estruturalismo. Teoria a qual segundo Ribeiro (2017), busca reconstruir saberes e vivências, além de ressignificar sentidos preestabelecidos (Ribeiro, 2017).

Neste sentido, faz-se necessário olhar para os elementos deste currículo mediante a teoria pós-crítica no que tange os aspectos da inovação, diferenças culturais, vislumbrando a formação de cidadãos críticos de forma autônoma e criativa, problematizando e questionando o significado do currículo, para movimentar os sentidos culturais, sociais, educacionais e políticos de nosso tempo, abrindo assim, possibilidades de ressignificação, principalmente na área educacional (Barbosa Silva \& Santos 2020).

No campo educacional brasileiro, o currículo pós-crítico busca transformações, pensando em práticas educacionais que apontem para uma multiplicação de sentidos, para as diversas linguagens que o currículo traz como verdades que podem ser modificadas, com novas possibilidades e invenções. É neste sentido que a teoria pós-crítica diz que o currículo não pode ser compreendido sem uma análise das relações de poder nas quais ele está envolvido (Barbosa Silva \& Santos 2020).

Um importante aspecto refere-se à formação dos educadores frente aos elementos deste currículo, visto a necessidade de integração de diferentes concepções acerca de costumes, valores, tradições e ideias para ir de encontro a pluralidade e a diversidade de reflexões em relação a tolerância e ao respeito, contudo é necessário que o docente tenha identificação com a 
proposta, além do compromisso social, político e ético para compreender as diversidades que permeiam a nossa sociedade (Donato, 2015).

Destaca-se que, alguns pontos da teoria crítica não foram detectados, a exemplo das questões de classe social, do capitalismo e do currículo oculto. Assim como, não foi possível identificar na teoria pós-crítica, aspectos considerados importantes como multiculturalismo, questões de sexualidade, gênero, raça e etnia, representação cultural e diferença.

Por fim, na Figura 1, são abordadas questões de identidade e alteridade, representadas no protagonismo dos sujeitos envolvidos no processo, que se aproximam das teorias pós-críticas. Essas teorias atribuem enfoque qualitativo à proposta curricular, assumindo as indagações subjetivas de cultura, poder, significação e representação como essenciais para a inovação curricular e para justiça social (Santomé, 2013; Saupe \& Geip, 2001).

A crítica a essas concepções sobre inovação curricular reside na teoria de Sacristán (2000), por afirmar que as estruturas escolares contribuem para manter a experiência alienada no trabalho dos professores e que o papel do professor pode estar em três níveis: imitação e manutenção, mediador e criativo-gerador, expressos nas quatro figuras desenhadas. No entanto, observou-se a hegemonia de modelos, teorias e práticas vinculados à pedagogia tradicional, visto que questões sociais e políticas emergiram apenas de modo superficial nos processos de inovação esboçados.

Outrossim, verifica-se a necessidade de fomentar o desenvolvimento de profissionais críticos e problematizadores, comprometidos com os processos de formação para a saúde, uma vez que as intervenções nessa área devem dispor de meios para envolver o contexto social dos indivíduos, incluindo os fatores orgânicos, psicológicos, socioeconômicos e espirituais.

Salienta-se a relevância de repensar novas possibilidades de ensinar e aprender, por se tratar de uma tarefa delicada, que demanda reorientação constante do processo formativo. Atualmente, algumas características das pedagogias predominantes na educação do Brasil ainda emergem no cotidiano de práticas educativas e se conflitam entre o ensinar e o aprender, as relações de poder e as necessidades de mercado.

Em vista disso, o processo de ensino-aprendizagem representa uma importante estratégia de análise crítica e avaliativa que permite repensar e transformar a formação por meio das próprias ações desenvolvidas, confrontando a teorização com a realidade.

\section{Considerações Finais}

Os relatos dos discentes, evidenciaram que os sentidos da inovação curricular perpassam pela superação/desconstrução do modelo tradicional de ensino-aprendizagem, em que pese apresentem elementos ainda hegemônicos.

Ao descortinar os elementos das teorias mediante análise dos desenhos, foi possível perceber que as teorias curriculares carregam interesses, e estão imergidas nas relações de poder, bem como, refletem questões sociopolíticas e econômicas da sociedade. Assim, resgatando a metáfora do cavalo de Troia, as teorias curriculares podem representar o "presente de grego" a depender do contexto e do pano de fundo onde estão inseridas. Além de possibilitarem ocultar práticas conservadoras e tradicionais por trás de supostas práticas inovadoras.

Diante do exposto, evidencia-se que não basta ter ideias e estratégias inovadoras, torna-se indispensável sensibilizar educadores e educandos para a implementação dessas novas metodologias e princípios pedagógicos, de modo a promover uma mudança consciente e sólida no processo educativo, que reverbera na formação de profissionais com enfoque para uma atuação voltada ao desenvolvimento das competências para resolução das demandas do cotidiano, e do mundo do trabalho e ao exercício da cidadania.

Dessa forma, neste estudo, foi possível perceber que a diferença entre as teorias se encontra na forma como concebem a natureza humana ou do conhecimento, da cultura e da sociedade. Porém, foi notório o quanto ainda estão presentes elementos 
hegemônicos da formação, enraizados nas práxis pedagógicas, currículos, conteúdos e atividades cotidianas. Assim, nota-se que a alteração da nomenclatura do componente inovações curriculares ou metodologias ativas-participativas, efetivamente, não assegura a mudança tão almejada ocorrerá.

Nessa perspectiva, pode-se afirmar que o campo das teorias pós-críticas ainda está em consolidação para reflexão/reconfiguração das práticas pedagógicas, sendo imprescindível reconhecer que há conflitos entre a inovação e modelos tradicionais, bem como há possibilidade da existência de práticas de ensino-aprendizagem que se dizem inovadoras estarem disfarçadas, porém impregnadas de conceitos e práticas ainda obsoletas, marcadas pelo viés tradicional e tecnicista, limitando o potencial emancipador d(n)a formação.

Por fim, este estudo apresenta como limitação a amostra ser constituída pelo relato apenas dos discentes da disciplina, autores do estudo, o que restringe os elementos identificados à ótica deste grupo. Por outro lado, recobra a relevância da reflexão sobre a temática e impulsiona futuros estudos.

\section{Referências}

Adorno, T. W., \& Horkheimer, M. (1985) A Dialética do Esclarecimento. Jorge Zahar.

Aguiar, F. P. M. (2017). O Currículo e a Prática Docente. Revista Científica Multidisciplinar Núcleo do Conhecimento, 02(1), 508-526

Audy, J. (2017). A inovação, o desenvolvimento e o papel da Universidade. Estudos Avançados. 31(90): 75-87.

Aurélio Silva, M. A. S.; Kaiser, A. R., \& Braga, R. F. (2018). Teoria curricular: e os dilemas das contradições. Revista Interação Interdisciplinar, 03(01), 3852. https://publicacoes.unifimes.edu.br/index.php/interacao/article/view/268.

Backes, D. S., Obem, M. K., Pereira, S. B., Gomes, C. A., Backes, M. T. S., \& Erdmann, A. L. (2015). Learning Incubator: an instrument to foster entrepreneurship in Nursing. Rev Bras Enferm.68(6):794-8. http://dx.doi.org/10.1590/0034-7167.2015680615i.

Baltar, P. (2020) As viradas na Teoria Crítica: A descolonialidade como crítica periférica. Tensões Mundiais, [S. l.], 16 (31), $21-47$.

Barbosa Silva, R. M. N., \& Santos, R. A. (2020). O currículo pós-crítico: uma experiência na escola de ensino fundamental em vitória/es. Nova revista amazônica, 8 (2), 195- 209. http://dx.doi.org/10.18542/nra.v8i2.9382

Bauer, M. W., \& Gaskell, G. (2008). Pesquisa qualitativa com texto, imagem e som: um manual prático. Petrópolis: Vozes.

Brasil. Ministério da Saúde. Conselho Nacional de Saúde. (2012). Resolução no 466, de 12 de dezembro de 2012 . Aprova as diretrizes e normas regulamentadoras de pesquisa envolvendo seres humanos. Brasília. https://bvsms.saude.gov.br/bvs/saudelegis/cns/2013/res0466_12_12_2012.html

Costa, D. A. S. ; Silva R. F. ; Lima, V. V. ; Ribeiro, E. C. O. National curriculum guidelines for health professions 2001-2004: na analysis according to curriculum development theories. Interface (Botucatu), 22(67), 1183-1195.

da Silva, L. A. A., Soder, R. M., Oliveski, C. C., \& Frizzo, M. N. (2018) Programa de Aprimoramento e Revitalização do Conhecimento na Enfermagem e Saude. Interface: Comunicação Saúde Educação, 22(65), 517. https://doi.org/10.1590/1807-57622016.0629

Donato, S. P. Contribuições da teoria pós-crítica na formação inicial de professores: entre desafios e possibilidades. https://educere.bruc.com.br/arquivo/pdf2015/16146_10142.pdf

Gondim, S. M. G., Feitosa, G. N., \& Chaves, M. (2007). A imagem do trabalho: um estudo qualitativo usando fotografia em grupos focais. Revista de Administração. Contemporânea. v. 11, n. 4, p. 153-174. https://doi.org/10.1590/S1415-65552007000400008.

Habowski, A. C., \& Conte, E. (2019). Repensar as tecnologias na educação a partir da teoria crítica. São Paulo: Pimenta Cultural.

Hargreaves, A. (2004). O Ensino na Sociedade do Conhecimento: A educação na era da insegurança. Porto Alegre: Artmed.

Horkheimer, M. (1990). Autoridade e família. In: Horkheimer, Max. Teoria crítica Tradução de Hilde Cohn. São Paulo, Perspectiva. 175-236.

Lopes, M. V. O. (2012). Sobre estudos de casos e relatos de experiência. Revista da Rede de Enfermagem do Nordeste. v.13, n4. http://www.periodicos.ufc.br/rene/article/view/4019.

Macedo, K. D.S., Acosta, B. S., Silva, E. B., Souza, N. S., Beck, C. L. C., \& Silva, K. K. D. (2018). Active learning methodologies: possible paths to innovation in health teaching. Escola Anna Nery. 22(3): 1-9. https://doi.org/10.1590/2177-9465-EAN-2017-0435.

Malta, S. C. L. (2013). Uma abordagem sobre currículo e teorias afins visando à compreensão e mudança. Revista Espaço do Currículo. 6(2): 340-354. http://dx.doi.org/10.15687/rec.v6i2.3732.

Mancilla, P. N. B., Backes, V. M. S., \& Canever, B. P. (2020). Learning styles: preference of the nursing students of the university of magallanes, chile. Texto contexto - Enfermagem. 29(spe). https://doi.org/10.1590/1980-265X-TCE-2019-0265. 
Research, Society and Development, v. 10, n. 12, e399101220515, 2021

(CC BY 4.0) | ISSN 2525-3409 | DOI: http://dx.doi.org/10.33448/rsd-v10i12.20515

Masetto, M. T. (2006). Mediação Pedagógica e o uso da tecnologia. Papirus.

Mendes, M. O. (2012). (Trad.). Ilíada de Homero. São Paulo: Montecristo Editora.

Netto, L., Silva, K. L., \& Rua, M. S. (2018). Reflective practice and vocational training: theoretical approaches in the field of Health and Nursing. Escola Anna Nery. 22(1): 1-6. https://doi.org/10.1590/2177-9465-EAN-2017-0309.

Ribeiro, M. D. P. (2016). Teorias críticas e pós-críticas: pelo encontro em detrimento do radicalismo. Movimento-Revista De educação, (5).

Sacristán, J. G. (2000). O currículo: uma reflexão sobre a prática. Artmed.

Santomé, J. T. (2013). Currículo escolar e Justiça Social. Penso.

Saupe, R., \& Geib, L. T. C. (2006). O processo de construção dos projetos polìtico pedagógicos na enfermagem. Rev Elet Enfermagem, 3(2). https://doi.org/10.5216/ree.v3i2.723.

Scarton, J., Claro, L. C., Paula, S. F. de, Perim, L. F., Ventura, J., \& Medeiros, S. P. (2020). Formação permanente: contribuições para a prática pedagógica do enfermeiro. Research, Society and Development, 9(3), e02932260. https://doi.org/10.33448/rsd-v9i3.2260.

Silva, T. T. (2011). Documentos de identidade: uma introdução as teorias curriculares. Autêntica.

Siqueira Silva, I., Xavier, P. B., \& Almeida, J. L. S. (2020). Empreendedorismo empresarial na Enfermagem: desafios, potencialidades e perspectivas. Research, Society and Development, 9(8), e912986348. https://doi.org/10.33448/rsd-v9i8.6348.

Trotte, L. A.C., Santos, J. L. G., Sarat, C. F. N., Mesquita, M. G.R., Stipp, M. A. C., Souza, P., Duarte, Q. G. M., Gobato, B. C., \& Lima, C. F. M. (2021). Entrepreneurial tendency of Nursing students: a comparison between graduating beginners and undergraduate students. Revista Latino-Americana de Enfermagem, 29, e3402: .https://dx.doi.org/10.1590/1518-8345.4397.3402. 